\title{
A new species of the genus Coleolaelaps (Acari: Laelapidae) associated with larvae of Polyphylla sp. (Coleoptera: Scarabaeidae) in Iran
}

\author{
Omid Joharchi*, Hadi Ostovan \& Alireza Saboori
}

Joharchi, O., Ostovan, H. \& Saboori, A. 2011: Anew species of the genus Coleolaelaps (Acari: Laelapidae) associated with larvae of Polyphylla sp. (Coleoptera: Scarabaeidae) in Iran. — Entomol. Fennica 22: 279-283.

Coleolaelaps ferdowsi Joharchi sp. n. (Acari: Laelapidae) was collected associated with the larval stage of Polyphylla sp. (Coleoptera: Scarabaeidae) on roots of peach trees in Neishabour, Khorasan Razavi, Iran. This new species is described and illustrations provided.

O. Joharchi (*corresponding author), Department of Entomology, Science and Research Branch, Islamic Azad University, Tehran, Iran. E-mail: j.omid2000 @gmail.com

H. Ostovan, Department of Entomology, Science and Research Branch, Islamic Azad University, Fars, Iran.E-mail: Ostovan2000@yahoo.com

A. Saboori, Department of Plant Protection, College of Agriculture, University of Tehran, Karaj, Iran.E-mail: saboori@ut.ac.ir

Received 17 June 2011, accepted 19 September 2011

\section{Introduction}

The genus Coleolaelaps Berlese, 1914 includes about 25 species. Members of the genus are morphologically similar to Hypoaspis Canestrini 1884. Joharchi and Halliday (2011) previously discussed the distinction between Coleolaelaps and Hypoaspis. Using those criteria, some species that have been described or classified in the genus Coleolaelaps are now considered as members of Hypoaspis. For example, Coleolaelaps liui Samšiňák, 1962, C. metasternalis Hyatt, 1964, C. coxalis Hyatt, 1964, C. striatus Hyatt, 1964, C. granulatus Hyatt, 1964, C. latisternalis Hyatt, 1964, C. simplexans Womersley, 1956, C. euputori Womersley, 1956, C. rhopaea Womersley, 1956, and C. allomyrinatus Ishikawa, 1968, all appear to be species of Hypoaspis s. str., because they have hypostomal setae $\mathrm{h} 3$ distinctly longer than other hypostomal setae, sternal shield fully developed with distinct anterior margin, approximately as wide as long and dorsal shield without lateral incisions at level between setae $\mathrm{j} 6$ and J1. Since then new species have been described from Turkey, Kazakhstan, China, and Japan, to bring the total to 14 species (Karg 1999). The only species that causes difficulties with this genus diagnosis is Coleolaelaps abnormalis Costa and Hunter, 1971, which lacks dorsal shield incisions, and has leg III shorter than or subequal to leg I. In other characters, C. abnormalis is clearly a species of Coleolaelaps. In this paper we describe another species which lacks dorsal shield incisions and is close to C. abnormalis.

\section{Materials and methods}

Laelapidae mites associated with the larval stage of Polyphylla sp. (Coleoptera: Scarabaeidae) 
were excavated and collected from soil in peach orchard trees in Neishabour, Khorasan Razavi province, Iran in March 2011 and placed in vials of $70 \%$ ethanol. Mites were removed from the larvae, cleared in Nesbitt's solution (Walter \& Krantz 2009) and mounted in Hoyer's medium (Walter \& Krantz 2009).

The nomenclature used for the dorsal idiosomal chaetotaxy is that of Lindquist and Evans (1965), the leg chaetotaxy is that of Evans (1963a), the palp chaetotaxy that of Evans (1963b), and names of other anatomical structures mostly follow Evans and Till (1979). All measurements in the descriptions are given in micrometres $(\mu \mathrm{m})$.

The holotype and some paratypes of the new species are deposited in the Acarological collection, Department of Plant Protection, Yazd Branch, Islamic Azad University (IAU); paratypes are also deposited in the Australian National Insect Collection, CSIRO Ecosystem Sciences, Canberra ACT, Australia (ANIC).

\section{Taxonomy}

\section{Genus Coleolaelaps Berlese}

Coleolaelaps Berlese, 1914: 141. Type species Laelaps (Iphis) agrestis Berlese, 1887, by original designation.

Coleolaelaps ferdowsi Joharchi sp. n. (Figs. 1-2)

Material examined. Holotype: female, Iran, Khorasan Razavi province, Neishabour city, H. Mokhtarisaveh leg., on larva of Polyphylla sp. (deposited in IAU). Paratypes: eight females, one male, same data as holotype; one female, Alborz, Karaj, $36^{\circ} 06^{\prime} \mathrm{N}, 50^{\circ} 38^{\prime} \mathrm{E}$, alt. 2,024 m a.s.1., 29.VII.2011, O. Joharchi leg., on larva of Polyphylla sp. (deposited in IAU and ANIC).

Description. Female $(n=5)$. Dorsal idiosoma. Dorsal shield length 970-1050, width at level of r3 460-470. Opisthonotal section narrower than podonotal section, without any lateral incisions (Fig. 1a). Podonotal region with 14 pairs of setae plus eight pairs of setae on lateral soft skin (s2, s3, s6, r2, r3, r4, r5, r6), z3 absent and s3 very long (372-396). Opisthonotal region with reticulation more distinct posterior to seta J3, with 11 pairs of setae on shield and approximately 21 pairs on lat- eral soft skin, S5 on the shield, other S series off the shield, S5 very long (292-346) and undulating. All setae except z1 long, j3 (292-298) and j4 (138-154) long enough to reach past j5 (154158), j6 (174-178) and J1 (108-124) long enough to reach past J2 (134-138), J4 (124-138) long enough to reach J5 and Z5, j5 (154-158) not long enough to reach $\mathrm{j} 6$.

Ventral idiosoma(Fig. 1b). Tritosternum(Fig. 1e) with paired pilose laciniae (198-248), columnar base $54-60 \times 34-40$ wide; pre-sternal area with indistinct granular ornamentation. Sternal shield (length 164-174) narrowest between st1st2 (100-114) and broadest at level of st3 (138142), longer than wide with straight anterior margin, entire surface with distinct polygonal ornamentation. Sternal setae long and smooth, st1 (108-124) off the shield, one pair of circular pores on anterior margin of sternal shield and a pair of circular pores between st 2 (124-128) and st3 (128-148). Metasternal setae st4 (124-134) located in soft skin, metasternal pores located on minute platelets. Endopodal plates I/II oval and minute, not fused to sternal shield, endopodal plates II/III triangular, not fused to sternal shield to varying degree in different specimens, endopodal plates III/IV elongate, narrow and curved. Genital shield long and tongue-shaped, length 316-346, maximum width 108-148, posterior edge rounded with two minute platelets outside the shield, surface with a few longitudinal lines, genital setae st5 (124-138) outside the shield. Paragenital pores located on soft skin close to st5. Anal shield triangular (158-178 $\times$ 134-138), its anterior half with lineate ornamentation, para-anal setae $(80-84)$ shorter than unpaired post-anal seta (100-108), cribrum large, anal pores indistinct. Opisthogastric skin with one pair of oval metapodal plates and 11 pairs of smooth setae including st5; JV5 very long and wavy. Exopodal plates behind coxa IV small and narrow. Peritrematal shields free, peritremes short, extending from coxa IV to posterior margin of coxa I, post-stigmatal section long and narrow, with three pair of post-stigmatal pores.

Gnathosoma. Epistome arched with anterior margin irregularly denticulate (Fig. 1d). Hypostomal groove with six rows of denticles (Fig. 1c), each with about 8-12 small teeth, and smooth anterior and posterior transverse lines. Hypo- 


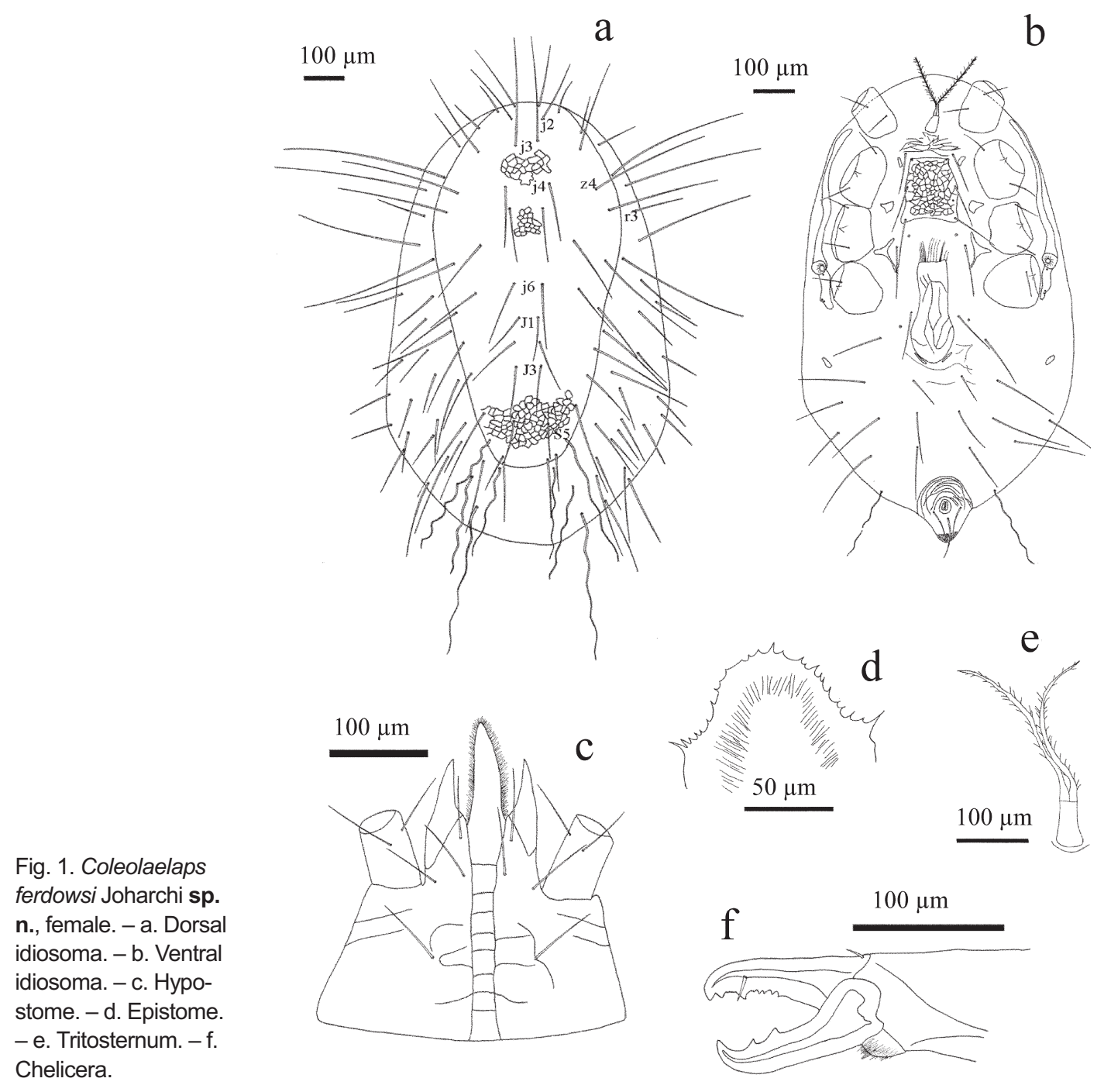

stome setae, all subequal in length (Fig. 1c). Corniculi robust and horn-like, reaching midlevel of palp femur. Palp chaetotaxy: trochanter 2 , femur 5 , genu 6 , tibia 12 , tarsus 15 , genu with a distinct dorso-distal triangular condyle, all setae smooth and needle-like, palp tarsal claw twotined. Fixed digit of chelicera with four small teeth, a larger median tooth, and one large distal tooth (Fig. 1f), pilus dentilis short and slender, dorsal seta short, thick, prostrate, movable digit with two large teeth, arthrodial membrane with a rounded flap and a few short filaments.

Legs. Leg III (1020-1050) subequal in length to leg I (1014-1040) and leg II (842-856) shortest, and leg IV (1504-1534) longest. Chaetotaxy:
Leg I: coxa 0 0/1 0/1 0 , trochanter $11 / 11 / 11$, femur $23 / 12 / 22$, genu $23 / 23 / 12$, tibia $23 / 23 / 12$. Leg II: coxa 0 0/1 0/1 0, trochanter $10 / 10 / 21$, femur 23/1 2/2 1 (pd1 and pd2 long, Fig. 2f), genu 2 $3 / 12 / 12$ (pd1, ad2 and $\mathrm{pd} 2$ long and ventral setae thick, Fig. 2f), tibia 2 2/1 2/1 2 (ventral setae thick). Leg III: coxa 0 0/1 0/1 0 , trochanter $11 / 1$ 0/1 1, femur 1 2/1 1/0 1 (al and av thick, Fig. 2e), genu 2 2/1 2/1 1 (ventral setae thick, Fig. 2e), tibia: 2 1/1 2/1 1 (pl, all and ventral setae thick). Leg IV: coxa 0 0/1 0/0 0, trochanter $11 / 10 / 1$, femur 1 2/1 1/0 1 (macroseta ad1 410-470, ad2 long 114-118, Fig. 2d), genu 2 2/1 3/0 2 (macrosetae ad1 406-460, ad2 long 108-142, all lateral setae thick, Fig. 2d), tibia 2 1/1 3/1 2 (lat- 

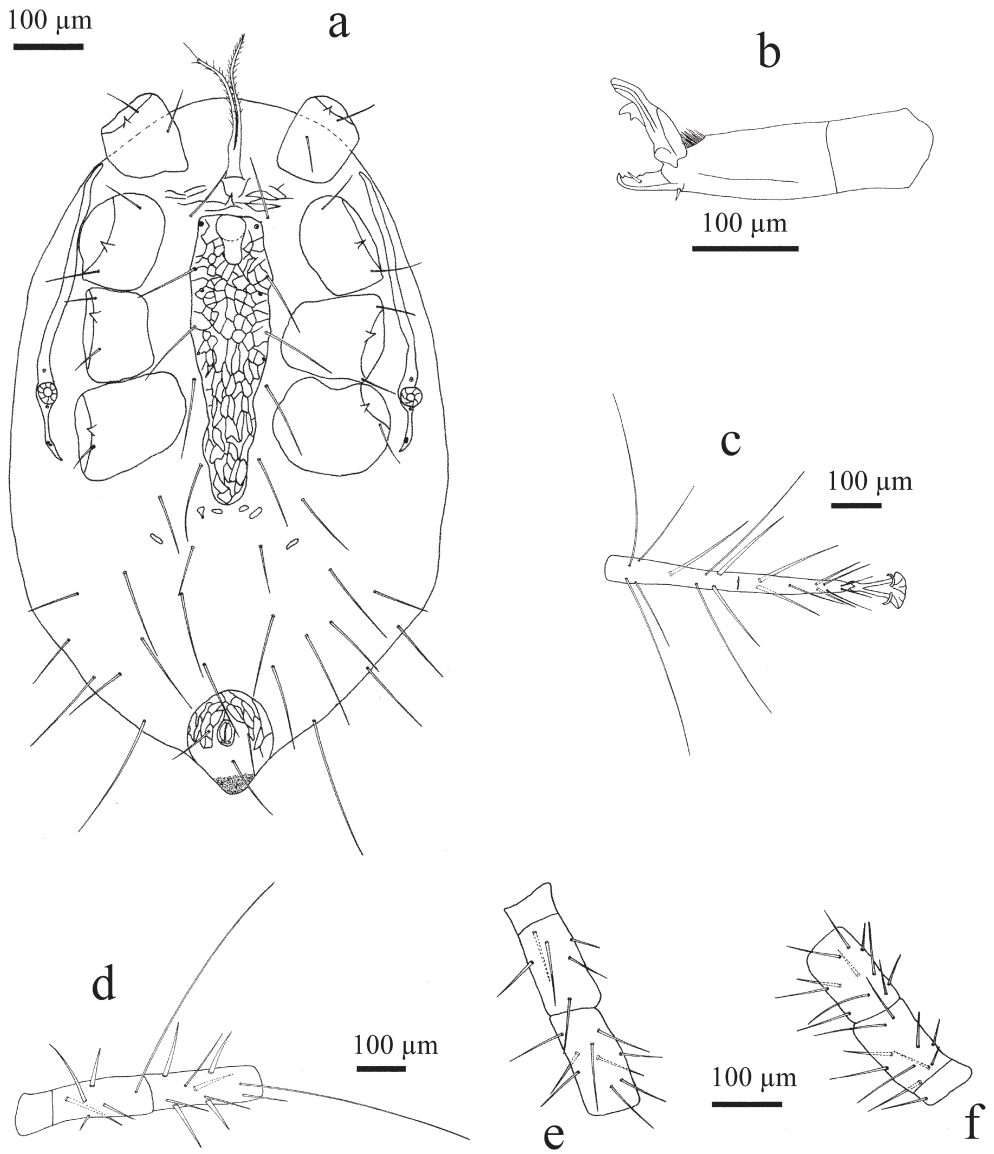

Fig. 2. Coleolaelaps ferdowsi Joharchi sp. n. - a. Ventral idiosoma, male. - b. Chelicera, male. - c. Tarsus IV, female. - d. Genu and femur IV, female. - e. Genu and femur III, female. $-f$. Genu and femur II, female. eral and ventral setae thick). Tarsi I-IV with 18 setae, $33 / 23 / 23+\mathrm{mv}$, md. On tarsus IV macrosetae ad2 (272-298), pd2 (262-298), ad3 (342-372), pd3 (372-382), long setae al3 (198208), pl3 (158-174) (Fig. 2c). All pre-tarsi with a pair of claws and a long thin membranous ambulacrum.

Insemination structures. Insemination ducts open on posterior margin of coxae III, sacculus indistinct, apparently unsclerotised.

Male $(n=1)$. Dorsal idiosoma. Dorsal shield length 850, width at level of r3 486; structure and chaetotaxy as for female.

Ventral idiosoma (Fig. 2a). Sternal, genital, endopodal and ventral shields fused to form a strongly ornamented composite shield and very short with two pairs of setae and three pairs of pores, posterior margin of the shield concave and irregular. Anal shield free, triangular, its anterior half with lineate ornamentation, unpaired post- anal seta longer than para-anal setae, cribrum large, anal pores indistinct.

Gnathosoma. Movable digit of chelicera (Fig. 2b) with one large tooth, spermatodactyl not much longer than the length of movable digit, with truncate tip, fixed digit with one medium distal tooth and minute pilus dentilis.

Legs. Chaetotaxy as in female, leg IV with several stout pointed spine-like setae on ventral surface of femur, genu and tibia.

Etymology. The species is named in memory of Hakim Abol Qasem Ferdowsi Tousi, one of the greatest Persian poets, author of the Shahnameh ("The Epic of Kings"), the Persian national epic.

Remarks. Coleolaelaps ferdowsi Joharchi sp. n. differs from all other species of the genus by the presence of ten setae on genu IV, a short peritreme, and 14 pairs of setae on the podonotal shield and without any lateral incisions, podonotal setae $\mathrm{j} 6$ are unusually long, $\mathrm{z} 3$ absent, and S5 very long and wavy. 


\section{Discussion}

All known species of Coleolaelaps are associated with melolonthine beetles in the genera Anoxia and Polyphylla, and the genus therefore has a Holarctic distribution which follows that of the host beetles. Costa and Hunter (1971) discussed extensive intra-specific variations in some species of Coleolaelaps, and that observation is confirmed by the species described here. The dorsal and sternal shields often have irregular and asymmetrical edges, and some setae may be found either on the edges of the shields or in the adjacent soft skin in different specimens, or on left and right sides of the same specimen. Species that cause difficulties with this genus diagnosis are Coleolaelaps abnormalis Costa and Hunter, 1971 and C. ferdowsi Joharchi sp. n., which lack incisions in the dorsal shield, and have leg III shorter than or subequal to leg I. Considering the other characters, C. abnormalis and C. ferdowsi Joharchi sp. n. clearly belong to Coleolaelaps. Costa and Hunter (1971) noted that maybe C. abnormalis is actually an aberrant form of $C$. agrestis Berlese, 1914 and should have no taxonomic standing of its own and only additional materials or works can solve this problem. But here we describe another species with the same two major characters as C. abnormalis.

The described species in the genus Coleolaelaps have been found mainly on the adults of melolonthine beetles and not on the larvae, except C. abnormalis and C. ferdowsi Joharchi sp. n. It is conceivable that all species associated with larvae of melolonthine beetles differ from the others in the genus by not having incisions on the dorsal shield and having leg III shorter than or subequal to leg I.

Acknowledgements. We are deeply grateful to Dr. Bruce Halliday from CSIRO Entomology, Canberra, Australia for his generous hospitality of the first author during his visit to Australia and his valuable help. We also thank Mr. Hossein Mokhtarisaveh (Department of Plant Protection, Jahrom Branch, Islamic Azad University) for his help in collecting the material and anonymous reviewers for their valuable comments.

\section{References}

Berlese, A. 1887: Acari, Myriopoda et Scorpiones hucusque in Italia reperta, 40. - 13 text pages + Plates 1-10. (Reprint by Junk, The Hague, 1979). [In Italian.]

Berlese, A. 1914: Acari nuovi. Manipulus IX. - Redia 10: 113-150 + Plates X-XIII. [In Italian.]

Canestrini, G. 1884: Prospetto dell'acarofauna Italiana. Atti del Reale Istituto Veneto di Scienze, Lettere ed Arti (Series 6) 2: 1563-1607. [In Italian.]

Costa, M. \& Hunter, P. E. 1971: The genus Coleolaelaps Berlese, 1914 (Acarina: Mesostigmata). — Redia 52: 323-360.

Evans, G. O. 1963a: Observations on the chaetotaxy of the legs in the free-living Gamasina (Acari: Mesostigmata). - Bulletin of the British Museum (Natural History) Zoology 10: 277-303.

Evans, G. O. 1963b: Some observations on the chaetotaxy of the pedipalps in the Mesostigmata (Acari). - Annals and Magazine of Natural History (Series 13) 6: 513-527.

Evans, G. O. \& Till, W. M. 1979: Mesostigmatic mites of Britain and Ireland (Chelicerata: Acari-Parasitiformes). An introduction to their external morphology and classification. - Transactions of the Zoological Society of London 35: 145-270.

Joharchi, O. \& Halliday, B. 2011: New species and new records of mites of the family Laelapidae (Acari: Mesostigmata) associated with Coleoptera in Iran. - Zootaxa 2883: 23-38.

Hyatt, K. H. 1964: A collection of Mesostigmata (Acari) associated with Coleopteran and Hemiptera in Venezuela. - Bulletin of the British Museum (Natural History) Zoology 2: 467-509.

Ishikawa, K. 1968: Studies on the mesostigmatid mites associated with the insects in Japan (1). - Reports of Research Matsuyama Shinonome Junior college 3: 27-218.

Karg, W. 1999: Zwei neue Raubmilbenarten der Gattung Coleolaelaps Berlese mit speziellem phoretischem Appetenzverhalten zu Coleopteren (Phyllophaga). Abhandlungen und Berichte des Naturkunde Museums zu Görlitz 71: 429-434.

Lindquist, E. E. \& Evans, G. O. 1965: Taxonomic concepts in the Ascidae, with a modified setal nomenclature for the idiosoma of the Gamasina (Acarina: Mesostigmata). - Memoirs of the Entomological Society of Canada 47: 1-64.

Samšiňák, K. 1962: Neue Entomophile Acari Aus China. - Časopis Československé Společnosti Entomologické 59: 186-204. [In XXX]

Walter, D. E. \& Krantz, G. W. 2009: Collection, rearing, and preparing specimens. - In: Krantz, G. W. \& Walter, D. E. (eds.), A manual of acarology: 83-96. Third Edition, Texas Tech University Press, Lubbock, Texas. $807 \mathrm{pp}$.

Womersley, H. 1956: On some new Acarina-Mesostigmata from Australia, New Zealand and New Guinea. Journal of the Linnean Society (Zoology) 42: 505599. 